\title{
Aging magnifies the effects of dopamine transporter and D2 receptor genes on backward serial memory
}

\author{
Shu-Chen $\mathrm{Li}^{\mathrm{a}}{ }^{\mathrm{b}, *}$, , Goran Papenberg ${ }^{\mathrm{a}}$, Irene E. Nagel ${ }^{\mathrm{c}}$, Claudia Preuschhof ${ }^{\mathrm{c}}$, Julia Schröder ${ }^{\mathrm{d}}$, \\ Wilfried Nietfeld ${ }^{\mathrm{d}}$, Lars Bertram ${ }^{\mathrm{d}}$, Hauke R. Heekeren ${ }^{\mathrm{c}}$, Ulman Lindenberger ${ }^{\mathrm{a}}$, \\ Lars Bäckman ${ }^{\mathrm{e}}$ \\ ${ }^{a}$ Max Planck Institute for Human Development, Center for Lifespan Psychology, Berlin, Germany \\ ${ }^{b}$ Department of Psychology, Technische Universität Dresden, Dresden, Germany \\ ${ }^{c}$ Department of Psychology and Educational Science, Freie Universität, Berlin, Germany \\ ${ }^{d}$ Max Planck Institute for Molecular Genetics, Berlin, Germany \\ ${ }^{e}$ Aging Research Center, Karolinska Institute, Stockholm, Sweden \\ Received 4 March 2012; received in revised form 17 July 2012; accepted 2 August 2012
}

\begin{abstract}
Aging compromises dopamine transporter (DAT) and receptor mechanisms in the frontostriatal circuitry. In a sample of 1288 younger and older adults, we investigated (i) whether individual differences in genotypes of the DAT gene (i.e., SLC6A3, the DAT variable number of tandem repeat 9/9,9/10, and 10/10) and in the D2 receptor (DRD2) gene (i.e., the C957T [rs6277] CC and any T) interactively contribute to phenotype variations in episodic memory performance; and (ii) whether these genetic effects are magnified in older adults, because of considerable declines in the dopamine functions. Our results showed that carrying genotypes associated with higher levels of striatal synaptic dopamine (DAT 9/9) and higher density of extrastriatal D2 receptors (C957T CC) were associated with better backward serial recall, an episodic memory task with high encoding and retrieval demands. Critically, the gene-gene interaction effect was reliably stronger in older than in younger adults. In line with the resource modulation hypothesis, our findings suggest that aging-related decline in brain phenotypes (e.g., dopamine functions) could alter the relations between genotypes and behavioral phenotypes (e.g., episodic memory).
\end{abstract}

(C) 2013 Elsevier Inc. All rights reserved.

Keywords: Aging; Dopamine; Genetics; DAT; SLC6A3; DRD2; Episodic memory; Serial recall

\section{Introduction}

Advances in molecular genetics have spurred interest in incorporating genetic methods into cognitive and neuroscience research (Green et al., 2008). Such hybrid approaches hold promise for elucidating molecular and biological mechanisms of cognitive phenotypes. Of particular relevance for the current study, intermediate phenotypes, such as brain mechanisms at neurochemical, structural, and functional levels (Meyer-Lindenberg and Weinberger, 2006),

\footnotetext{
* Corresponding author at: Department of Psychology, Technische Universität Dresden, Zellescher Weg 17, D-01062, Dresden, Germany. Tel: +490351 46334162; fax: +49035146337294.

E-mail address: li@psychologie.tu-dresden.de (S.-C. Li).
}

change substantially during maturation and senescence. Thus, it has been hypothesized that age-related differences in brain resources might modulate genotype-phenotype relations during different life periods (Lindenberger et al., 2008; Posner et al., 2006; Wahlstrom et al., 2010). Genes related to the neurotransmitter dopamine (DA) represent a case in point. Evidence from clinical (Mattay et al., 2003; Weinberger et al., 2001) and animal (Vijayraghavan et al., 2007) studies as well as neurocomputational simulations (Li et al., 2001; Li and Sikström, 2002) suggests that the relation between DA signaling and cognitive performance follows an inverted-U function (see Cools and D'Esposito, 2011, for review). The nonlinear function relating DA modulation to cognitive per- 
formance predicts that genetic effects on cognition would be more apparent when DA signaling recedes from an optimal level, such as in old age (Lindenberger et al., 2008).

Initial findings from three age-comparative studies lend support to this resource-modulation hypothesis. For instance, older adults' spatial working memory and executive functions were associated with individual differences in genetic predispositions of the gene that codes for the catechol- $O$-methyltransferase, an enzyme that degrades DA in prefrontal cortex, whereas no such relation was observed in younger adults (Nagel et al., 2008; Störmer et al., 2012). A similar age magnification effect has been extended to cognitive functions that implicate other intermediate phenotypes. In younger adults, variations in the gene coding for the brain-derived neurotrophic factor (BDNF) are associated with individual differences in hippocampal and frontal volumes (Pezawas et al., 2004). Age-related decline in hippocampal volume (Raz et al., 2009) may render a larger effect of the BDNF genotype on performance that relies on hippocampal function, such as episodic memory. In agreement with this assertion, an association between BDNF genotype and episodic memory performance was observed under high associative demands in older, but not in younger adults (Li et al., 2010).

Thus far, most studies on adult age differences in genotype-phenotype relations have been restricted to the effect of single genes (e.g., Li et al., 2010; Störmer et al., 2012; for an exception, see Nagel et al., 2008). Given that complex phenotypes, such as memory, draw on multiple neurobiological substrates and are thus influenced by multiple genes (e.g., Bertolino et al., 2006; 2009; Markett et al., 2011; Nagel et al., 2008; Preuschhof et al., 2010), it is imperative to further investigate the resource-modulation hypothesis in relation to gene-gene interactions. Based on this consideration, and in light of the age-related decline in various preand postsynaptic components of the DA system (for reviews, see Bäckman et al., 2006, 2010), we investigated (i) whether genes relevant to pre- and postsynaptic components of the DA system contribute interactively to individual differences in episodic memory performance; and (ii) whether such interactive effects are magnified in old age.

Going beyond the well-studied relation of DA to working memory and executive functions (see Seamans and Yang, 2004, for review), recent studies also demonstrate a role of DA in modulating episodic memory (see Lisman and Grace, 2005; Shohamy and Adcock, 2010, for reviews). Serial recall is of special interest here, because it involves long-term associative memory that draws on medial-temporal lobe structures (Fortin et al., 2002) as well as working memory for order information that is subserved by the prefrontal and parietal cortices (Botvinick and Watanabe, 2007; Marshuetz and Smith, 2006; Talmi et al., 2005). Therefore, the phenotype we focused on was serial-order memory (Ebbinghaus, 1885; Lewandowsky and Murdock, 1989). In particular, we targeted backward serial recall, as it requires more complex retrieval operations and has greater associative demands than free or forward recall ( $\mathrm{Li}$ and Lewandowsky, 1993, 1995; Thomas et al., 2003). As a result, backward serial recall may be especially sensitive to genetic effects.

Specifically, given the evidence for (1) clear aging-related decline in the striatal DA transporter (Erixon-Lindroth et al., 2005; Rinne et al., 1998; Troiano et al., 2010) as well as in D2 receptor binding (Bäckman et al., 2000; Kaasinen et al., 2000); and (2) their involvements in episodic memory (Cervenka et al., 2008; Erixon-Lindroth et al., 2005; Morcom et al., 2010; Takahashi et al., 2007), we focused on the effects of the DA transporter (DAT) gene and the D2 receptor gene on backward serial memory.

The human DAT gene (SLC6A3) displays a polymorphic 40-base pair (bp) variable number of tandem repeat (VNTR). The 40-bp VNTR element is repeated between 3 and 13 times and occurs with highest frequency in the 9and 10-repeat forms (Mitchell et al., 2000; Vandenbergh et al., 1992). The DAT VNTR polymorphism has been related to striatal DAT availability both in vitro (Miller and Madras, 2002; VanNess et al., 2005) and in vivo (Cheon et al., 2005; Heinz et al., 2000; Jacobsen et al., 2000; van de Giessen et al., 2009). In vivo data from human imaging studies show that DAT VNTR 10-repeat homozygotes express higher striatal DAT density than 9/10-repeat carriers (Cheon et al., 2005; Heinz et al., 2000). The higher availability of DAT in 10-repeat homozygotes might result in increased clearance of synaptic DA, and thus lower striatal synaptic DA levels. Consistent with the DA-cognition link, an advantage of 9-repeat carriers in executive functions (Loo et al., 2003), working memory (Brehmer et al., 2009), episodic memory (Schott et al., 2006), and sequential learning (Simon et al., 2011) has been reported, although some studies have failed to demonstrate such an association (Boonstra et al., 2008; Rommelse et al., 2008). The C957T (rs6277) single nucleotide polymorphism (SNP) of D2 receptor gene (DRD2) affects messenger RNA (mRNA) stability. Specifically, the $\mathrm{T}$ allele of the C957T SNP has been linked to reduced mRNA stability, affecting the density of D2 receptors (Duan et al., 2003). This allele has also been associated with reduced extrastriatal D2 receptor availability (Hirvonen et al., 2009a) and lower striatal DA levels (Hirvonen et al., 2009b).

In sum, we expected that striatal synaptic DA levels as well as extrastriatal D2 receptor availability would be higher in individuals carrying the DAT VNTR 9-repeat and D2 receptor C957T C alleles. Given the role of DA in modulating frontalhippocampal memory processes (Cervenka et al., 2008; Erixon-Lindroth et al., 2005; Morcom et al., 2010; Takahashi et al., 2007), we expected these individuals to perform better in backward serial recall. Further, on the basis of the resourcemodulation hypothesis (Lindenberger et al., 2008), these effects should be magnified in old age. 
Table 1

Demographic variables, DAT and D2 receptor (C957T) genotypes, and vascular health indicators in younger and older adults

\begin{tabular}{|c|c|c|c|c|c|c|c|}
\hline \multirow{3}{*}{$\begin{array}{l}\text { Genotype } \\
\text { C957T } \\
\text { DAT }\end{array}$} & \multicolumn{6}{|c|}{ Younger adults $(n=479)$} & \multirow[t]{3}{*}{ Note } \\
\hline & \multicolumn{3}{|l|}{$\mathrm{CC}$} & \multicolumn{3}{|l|}{ Any $\mathrm{T}$} & \\
\hline & $9 / 9$ & $9 / 10$ & $10 / 10$ & $9 / 9$ & $9 / 10$ & $10 / 10$ & \\
\hline \multicolumn{8}{|l|}{ Demographics } \\
\hline$n$ & 6 & 39 & 46 & 23 & 146 & 219 & \\
\hline Age range & $21-28$ & $21-31$ & $21-31$ & $19-32$ & $20-31$ & $20-32$ & \\
\hline Age, mean (SD) & $25.4(2.8)$ & $26.1(2.9)$ & $26.7(2.8)$ & $26.3(3.2)$ & $26.2(3.0)$ & $25.9(3.0)$ & a \\
\hline Female/male & $4 / 2$ & $23 / 16$ & $17 / 29$ & $12 / 11$ & $78 / 68$ & $122 / 97$ & b \\
\hline Education, y, mean (SD) & $12.7(1.4)$ & $12.6(1.5)$ & $13.3(1.2)$ & $12.7(0.9)$ & $12.5(1.2)$ & $12.4(1.2)$ & $\mathrm{c}$ \\
\hline State of health, mean (SD) & $4.3(0.8)$ & $4.2(0.6)$ & $4.2(0.6)$ & $4.3(0.6)$ & $4.2(0.6)$ & $4.2(0.7)$ & a \\
\hline BDNF ValVal/any Met & $3 / 3$ & $17 / 22$ & $33 / 13$ & $15 / 8$ & $95 / 50$ & $145 / 74$ & $\mathrm{~b}$ \\
\hline \multicolumn{8}{|l|}{ Vascular health indicator } \\
\hline Cardiovascular disease, $\%$ & 16.70 & 2.60 & 0 & 17.40 & 6.20 & 3.20 & c \\
\hline Hypertension medication, \% & 0 & 0 & 0 & 0 & 0 & 1.40 & c \\
\hline Hypertension grade, mean (SD) & $0.83(0.98)$ & $0.72(0.83)$ & $0.65(0.74)$ & $0.57(0.66)$ & $0.61(0.71)$ & $0.65(0.72)$ & a \\
\hline Hypertensive, $\%$ & 50 & 53.8 & 50 & 52.2 & 50 & 53 & $\mathrm{~b}$ \\
\hline Genotype & \multicolumn{6}{|c|}{ Older adults $(n=809)$} & \\
\hline C957T & \multicolumn{3}{|l|}{$\mathrm{CC}$} & \multicolumn{3}{|l|}{ Any $\mathrm{T}$} & \\
\hline DAT & $9 / 9$ & $9 / 10$ & $10 / 10$ & $9 / 9$ & $9 / 10$ & $10 / 10$ & \\
\hline \multicolumn{8}{|l|}{ Demographics } \\
\hline$n$ & 12 & 69 & 113 & 37 & 238 & 340 & \\
\hline Age range & $60-70$ & $60-71$ & $60-71$ & $61-70$ & $60-71$ & $59-71$ & \\
\hline Age, mean (SD) & $65.3(3.3)$ & $65.1(2.7)$ & $65.4(3.0)$ & $65.2(3.2)$ & $65.2(2.7)$ & $65.2(2.8)$ & $\mathrm{a}$ \\
\hline Female/male & $3 / 9$ & $43 / 26$ & $62 / 51$ & $22 / 15$ & $142 / 96$ & $215 / 125$ & $\mathrm{~b}$ \\
\hline Education, mean y (SD) & $10.9(1.6)$ & $11.1(1.6)$ & $10.9(1.7)$ & $10.5(1.7)$ & $10.9(1.9)$ & $10.7(1.7)$ & a \\
\hline State of health, mean (SD) & $4.0(0.6)$ & $3.9(0.7)$ & $4.0(0.6)$ & $3.8(0.6)$ & $3.9(0.6)$ & $3.9(0.6)$ & a \\
\hline BDNF ValVal/any Met & $11 / 1$ & $49 / 20$ & $84 / 29$ & $23 / 14$ & $148 / 90$ & $215 / 124$ & b \\
\hline \multicolumn{8}{|l|}{ Vascular health indicator } \\
\hline Cardiovascular disease, $\%$ & 41.70 & 36.20 & 36.30 & 51.40 & 39.50 & 35.30 & a \\
\hline Hypertension medication, \% & 25 & 29.00 & 32.70 & 48.60 & 32.80 & 30.90 & $\mathrm{~b}$ \\
\hline Hypertension grade, mean (SD) & $1.58(0.90)$ & $1.45(0.99)$ & $1.71(0.99)$ & $1.59(1.1)$ & $1.52(0.97)$ & $1.59(1.0)$ & a \\
\hline Hypertensive, $\%$ & 100 & 85.5 & 88.5 & 86.5 & 86.6 & 87.6 & $\mathrm{~b}$ \\
\hline
\end{tabular}

State of health is based on 4 self-ratings on a 5-point scale (1, poor; 5, excellent).

Key: BDNF, brain-derived neurotrophic factor; DAT, dopamine transporter.

${ }^{\text {a }}$ One-way analysis of variance $=$ not significant.

${ }^{\mathrm{b}}$ Chi-square test $=$ not significant.

${ }^{\mathrm{c}}$ One-way analysis of variance $=$ significant $(\mathrm{p}<0.05)$.

\section{Methods}

\subsection{Participants}

Healthy volunteers $(n=1288)$ from 2 age groups were examined: 479 younger adults (mean age $=26.1, \mathrm{SD}=$ 2.96 , range $=19-32 ; 256$ females and 223 males) and 809 older adults (mean age $=65.2, \mathrm{SD}=2.8$, range $=$ 59-71; 487 females and 322 males). All participants were Caucasian, right-hand dominant, and had normal to corrected vision. No participants reported a history of head injury, medical (e.g., heart attack), neurological (e.g., epilepsy), psychiatric (e.g., depression) diseases, and none were taking medications that affect DA system or memory functions. All older participants scored over 27 on the Mini Mental State Examination. Given that earlier studies suggested that vascular health might affect cognitive function in old age and interact with genetic effects (e.g., Raz et al., 2009), we also assessed relevant indicators of vascular health (diagnoses of cardiovascular disease and arterial hypertension). Importantly, the DAT and C957T genotype groups did not differ with respect to the percentage of participants with hypertension or a derived measure of hypertension grade computed according to the guidelines published by the World Health Organization together with the International Society of Hypertension (WHO, ISH Writing Group, 2003; see Table 1 for details). All participants were recruited in Berlin via newspaper announcements, posters in public transportation, and postcards in restaurants and pubs. Participants gave informed consent and were paid $€ 7$ per hour for their participation. The ethics committee of the Charité Universitätsmedizin Berlin approved the study.

\subsection{Genotyping}

DNA was extracted from peripheral blood using standard methods. All genotyping was performed at the Max Planck Institute for Molecular Genetics. For the DAT gene (SLC6A3), we genotyped the 40-base-pair VNTR in the 3' 
untranslated region following previously published procedures (Lim et al., 2006; Vandenbergh et al., 1992). For the amplification of the region flanking the DAT1 40-bp VNTR the following oligonucleotide primers were used: 5'-TGTGGTGTAGGGAACGGCCTGAGA-3' (forward) and 5' TGTTGGTCTGCAGGCTGCCTGCAT-3' (reverse) yielding amplicon sizes of approximately $470 \mathrm{bp}$ (representing the 10-repeat allele). Product amplification was achieved by polymerase chain reaction on 96-well microtiter plates in $10-\mu \mathrm{L}$ reaction volumes. For each reaction we combined $1.5 \mu \mathrm{M}$ of each primer, $10 \mathrm{ng}$ of DNA template, $0.25 \mathrm{mM}$ dNTPs (deoxyribonucleoside triphosphate), $0.25 \mathrm{U}$ Taq polymerase and Q solution (Qiagen, Ltd., Hilden, Germany). Thermal cycling was done on an MJ Research (Waltham, MA, USA), Thermo Cycler PTC-240 using the following cycling conditions: initial denaturation at $94{ }^{\circ} \mathrm{C}$ (3 minutes), followed by 35 cycles of denaturation at $94{ }^{\circ} \mathrm{C}$ (45 seconds), annealing at $70{ }^{\circ} \mathrm{C}$ (90 seconds), and extension at $72{ }^{\circ} \mathrm{C}$ (35 seconds), followed by a final extension step at $72{ }^{\circ} \mathrm{C}$ (6 minutes). Genotypes were called after visualization of amplification products on a Shimadzu MCE-202 MultiNA instrument (Shimadzu Corporation, Kyoto, Japan) using the DNA 500 kit following the manufacturer's protocol. In this assay, the 9-repeat allele ran at approximately $430 \mathrm{bp}$, while the 10-repeat allele ran at approximately $470 \mathrm{bp}$. Genotyping efficiency in the full sample was $99.2 \%$. Individuals carrying at least 1 non- 9 or non-10-repeat allele $(n=50$ [2.8\%]) were excluded from subsequent analyses.

The polymorphism (C957T [rs6277]) of the dopamine D2 receptor gene (DRD2) was genotyped using a commercially available allelic discrimination assay (C_11339240_ 10 for rs6277; TaqMan SNP genotyping Assay; Applied Biosystems, Foster City, CA, USA). Genotyping of SNPs was performed on $250 \mathrm{ng}$ of DNA template in 384-well format using TaqMan chemistry according to manufacturer's instructions on an "OpenArray" multiplex genotyping instrument (Applied Biosystems). Genotypes were called after visualization and clustering using Applied Biosystems "Autocaller" software version 1.1. All automatically called genotype clusters were inspected independently and blind to phenotypic status by 2 laboratory members and manually recalled where necessary. On average, efficiency of the multiplex genotyping run was $>98 \%$, with an error rate below $0.2 \%$ (based on over $>1500$ genotypes generated across HapMap samples run in multiples on each genotyping plate). Only samples for which genotypes at both polymorphisms (and phenotypic data, see below) were available were used in subsequent analyses. Table 1 shows the allelic frequencies in our sample along with demographic information. Regarding the DAT gene (SLC6A3), the genotype distribution of the entire sample was in Hardy-Weinberg equilibrium, $\chi_{\text {VNTR DAT }}^{2}(1)=0.27, p=0.60$. Similarly, genotypes for the C957T SNP of the D2 receptor gene
(DRD2) were in Hardy-Weinberg equilibrium in the full sample, $\chi_{\text {C957T }}^{2}(1)=2.57, p=0.11$.

\subsection{Phenotype: backward serial recall}

Participants underwent group testing that involved 5 to 6 individuals of the same age group. They were presented with 3 different lists containing 12 words each. Following presentation of the last word in each list, participants were asked to recall the list of words in sequence, starting from the word presented last going backward in sequence to the word that was presented first. If the participants could not recall a particular word, they could skip that position and move on to the next. However, once the participants decided to skip a position, they could not go back to that position and provide a response for it. Responses were scored using a strict serial-recall criterion: an accurate response required that both the identity of a word and its serial position were correct. Errors were categorized as transpositions (words correctly recalled but in the wrong positions), omissions (words not recalled), commissions (recall of nonstudied words), extralist intrusions (recall of words from other lists), and repetitions (recall of a word more than once). Here, we focused on mean transposition and omission errors, because the other error types were very rare.

\subsection{Statistical analysis}

Demographic data were analyzed with analysis of variance or $\chi^{2}$ tests, using SPSS for Windows 15.0 (SPSS, Chicago, IL, USA). Using SAS 9.1 for Windows (SAS Institute, Inc., Cary, NC, USA). Behavioral data were analyzed with mixed-effect models with maximum likelihood estimation (Proc Mixed procedure), if inequality of variances between groups was observed. In contrast to standard analysis of variance, mixed-effect models allow for differences in variances and covariance between age groups and genotypes, which are more suitable for measures that show multivariate heterogeneity of variances. Specifically, the Levene's test of equality of error variance for recall accuracy across the majority of serial positions and for omission errors were significant $(p<0.001)$, indicating multivariate heterogeneity of variance in these 2 measures. Thus, the Proc Mixed procedure with fixed and random effects was used to analyze these 2 measures. Instead of estimating effect sizes using the common index of partial $\eta^{2}$, given that we used the mixed-effect models with fixed and random effects, we estimated effect sizes by the intraclass coefficient (ICC), which has been recommended to be more suitable for models that include random effects and/or repeated measures designs (Fern and Monroe, 1996; Maxwell et al., 1981). Given the well-established female superiority in episodic memory (see Herlitz and Rehnman, 2008, for review) and earlier findings indicating that the BDNF polymorphism contributes to individual differences in episodic memory (Egan et al., 2003; Hariri et al., 2003; Li et al., 
2010), both sex and the BDNF polymorphism were used as covariates in all subsequent analyses.

\section{Results}

\subsection{Recall accuracy}

Analyzing the effects of age (younger vs. older), DAT VNTR (9/9, 9/10, and 10/10), and C957T (CC vs. any T) genotypes across the 12 serial positions, we found significant effects for the 4 factors: age, $F(1,660)=1299.84$, $\mathrm{ICC}=0.814, p<0.05$; DAT VNTR, $F(2,905)=28.43$, $\mathrm{ICC}=0.24, p<0.05 ;$ C957T, $F(1,656)=32.22, \mathrm{ICC}=$ $0.30, p<0.05$; and serial position, $F(11,654)=1.81$, ICC $=0.17, p<0.05$. The age $\times$ serial position interaction was reliable, $F(11,654)=12.10$, ICC $=0.41, p<$ 0.05 , with larger serial position effects in older than in younger adults. The significant age $\times$ C957T interaction, $F(1,666)=11.79$, ICC $=0.13, p<0.05$, indicated that the $\mathrm{D} 2$ receptor genotype effect was stronger in older than in younger adults. The DAT VNTR $\times$ C957T interaction, $F(2,905)=16.74$, ICC $=0.19, p<0.05$, reflected that the DAT and D2 receptor genes modulated each other's effects on backward serial recall. Specifically, the beneficial effect of carrying the DAT 9/9 genotype, associated with higher striatal synaptic DA levels, was larger in the individuals who also carried the C957T CC genotype, associated with higher striatal DA levels and higher extrastriatal D2 receptor density. Most critically, the 3-way interaction among age, DAT VNTR, and C957T, was reliable, $F(2,912)=6.84$, ICC $=0.12$, $p<0.05$, reflecting that the gene-gene interaction effect was larger in older adults (Fig. 1). These findings suggest that, as aging constrains the efficacy of the pre- and postsynaptic components of the DA system, variations in DA-related genes yield stronger effects on episodic memory.

\subsection{Error scores}

We also performed separate analyses on 2 main error types: omission and transposition errors. In general, older adults made more errors than younger adults with respect to both error types $(p s<0.001)$. Moreover, we found a significant age $\times$ error type interaction, $F(1,908)=31.45, p<$ 0.05 , reflecting that older adults made more omission than transposition errors (cf. Maylor, Vousden, \& Brown, 1999; Unsworth \& Engle, 2006), whereas error frequency did not differ reliably as a function of error type in younger adults (Fig. 2). The phenotype variations in omission errors were significantly associated with individual differences in both genotypes (Fig. 2A). Specifically, omissions were affected by DAT VNTR, $F(2,1364)=74.24$, ICC $=0.31, p<0.05$; and C957T, $F(1,1066)=133.1$, ICC $=0.33, p<0.05$. The age $\times$ DAT VNTR, $F(2,1374)=28.83$, ICC $=0.20, p<$ 0.05 ; and DAT $\times$ C957T VNTR, $F(2,1364)=38.2$, ICC $=$ $0.23, p<0.05$ interactions, were significant. Critically, the age $\times$ DAT VNTR $\times$ C957T interaction was also significant, $F(2,1374)=29.09$, ICC $=0.20, p<0.05$, indicating that the effect of genetic epistasis for omission errors was larger in older than younger adults (Fig. 2A). Older adults whose genotypes are associated with higher striatal DA levels and extrastriatal D2 receptor densities made less omissions. In contrast, the main effects of DAT VNTR and C957T on transposition errors were nonsignificant $(F \mathrm{~s}<1$; Fig. 2B).

\section{Discussion}

We observed effects of the DAT and D2 receptor genes as well as their interactive influence on backward serial memory. Homozygotic DAT 9-repeat and C957T C carriers showed higher overall recall accuracy and made fewer omission errors. The observed gene-gene interactions are in line with animal and human studies showing that the DAT and D2 receptors are involved in regulating the prefrontostriatal-medial temporal circuitry critical to episodic memory (Cervenka et al., 2008; Erixon-Lindroth et al., 2005; Kellendonk et al., 2006; Kimberg et al., 2001; Mozley et al., 2001), as well as with studies focusing directly on interactions between the DAT and DA receptors at molecular and brain levels (e.g., Bertolino et al., 2009; Kimmel et al., 2001; Lee et al., 2007). Of key importance, in agreement with the resource-modulation hypothesis (Lindenberger et al., 2008), the observed genetic effects were larger in older than in younger adults, which underscores the importance of taking age-related changes in brain phenotypes (e.g., DA functions) into account when investigating genotype-phenotype relations.

An earlier study has shown that, although the DAT genotype did not affect recognition memory in younger adults, midbrain activation during encoding was greater in 9-repeat than in 10-repeat carriers (Schott et al., 2006). Similarly, another study of younger adults showed that the DAT genotype did not affect working memory, even though 10-repeat homozygotes showed reduced activation in prefrontal regions during task performance (Bertolino et al., 2009), likely reflecting lower striatal DA activity projecting through the frontostriatal pathway (Landau et al., 2009). Considering these results in light of the current findings, it appears that as behavioral phenotypes (e.g., cognitive performance) are more distal from genetic effects than intermediate brain phenotypes (e.g., functional activation, DA modulation), age-related differences in DA signaling would affect the genotypephenotype relations. In particular, effects of DA genes on cognitive phenotypes may be stronger in individuals whose brain resources (e.g., as DAT or DA receptors) function suboptimally, such as in older adults. Further, individual differences in DAT and D2 receptor genotypes were associated with omissions but not transposition errors. Carriers of the DAT 9/9 genotype and the C957T 
Younger Adults
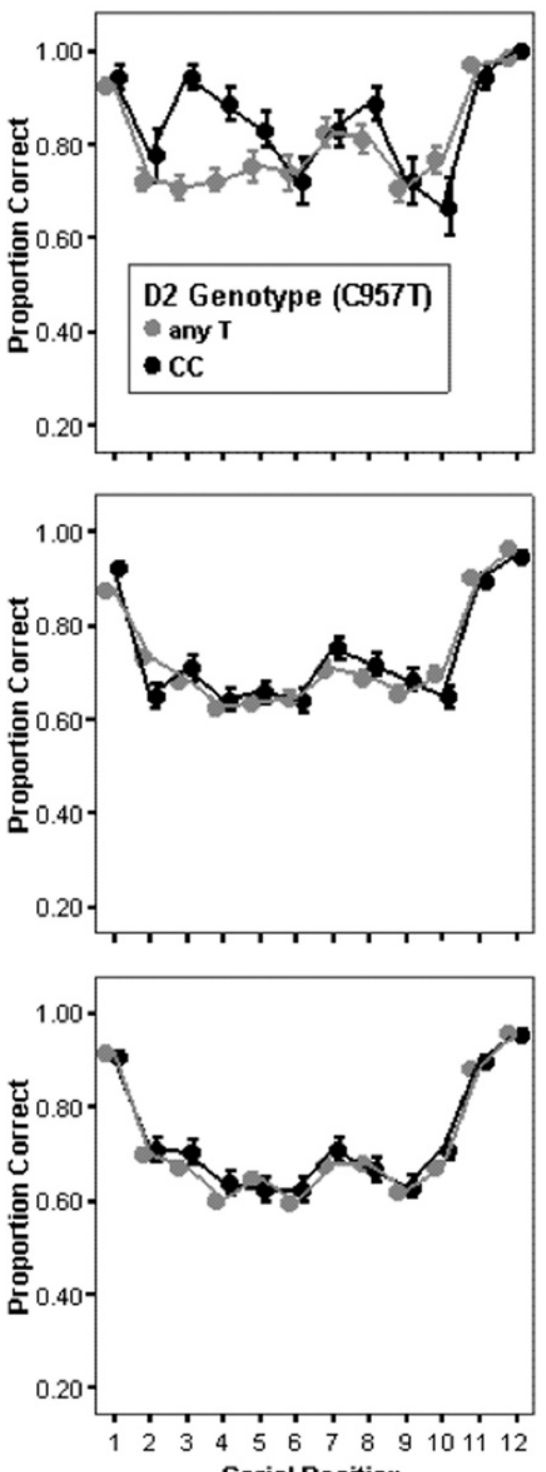

Older Adults
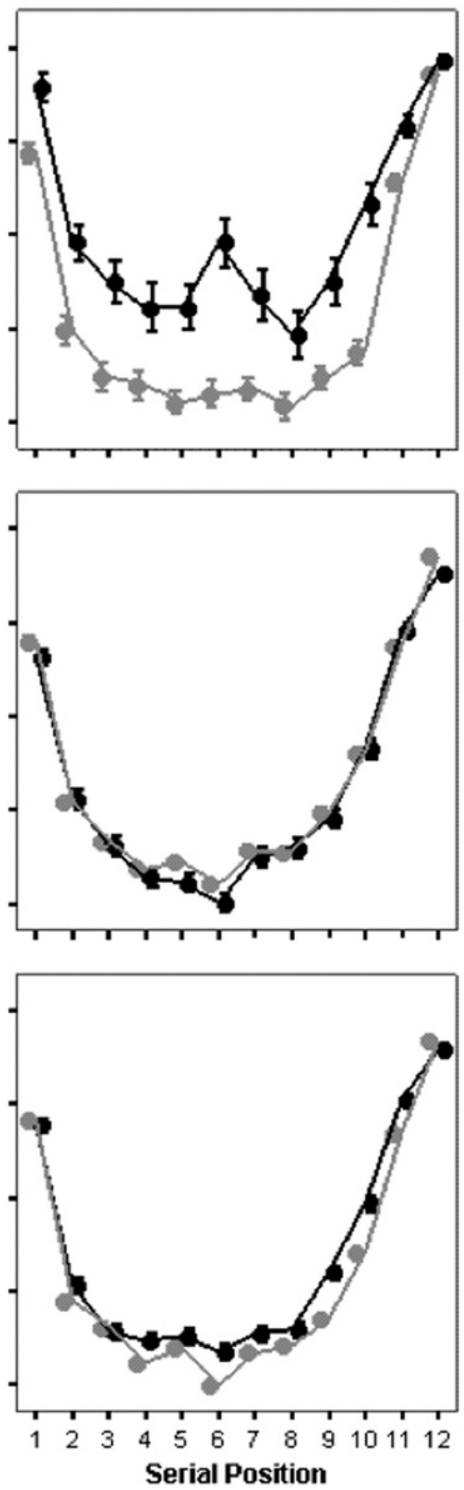

\section{DAT Genotype}

DAT $9 / 9$

DAT $9 / 10$

DAT 10/10

Fig. 1. Backward serial recall performance across age, genotype groups, and serial position (error bars are standard errors around the means).

CC genotype made fewer omissions than carriers of the other genotype combinations, and this effect was stronger in older adults. Research on serial memory has linked different error types to problems in different aspects of memory processing (see Farrell and Lewandowsky, 2002, for review). Omissions are usually associated with weaker encoding strength of single memory items (e.g., Hulme et al., 1997; Maylor et al., 1999), whereas transposition errors are typically attributed to problems in forming associations between items. Thus, our data suggest that older individuals who carry disadvantageous genotypes of the DAT and D2 receptor genes have particular difficulties in forming strong item memory traces. However, as for any genetic association study, these results should be confirmed in future studies with independent datasets before this association can be considered as established. Indeed, findings regarding phenotypic effects of these two polymorphisms have been inconsistent. For instance, some authors have reported greater, rather than reduced, DAT binding potential in 9/9 and $9 / 10$ repeat carriers compared with 10/10 carriers (Jacobsen et al., 2000; van de Giessen et al., 2009), and others have found that DRD2 957T carriers performed better in a working memory task than DRD2 957C homozygotes (Jacobsen et al., 2006). These inconsistencies may reflect between-study differences in radioligands, sample characteristics, sample sizes, and the specific cognitive functions assessed. At the same time, such incon- 
(A)

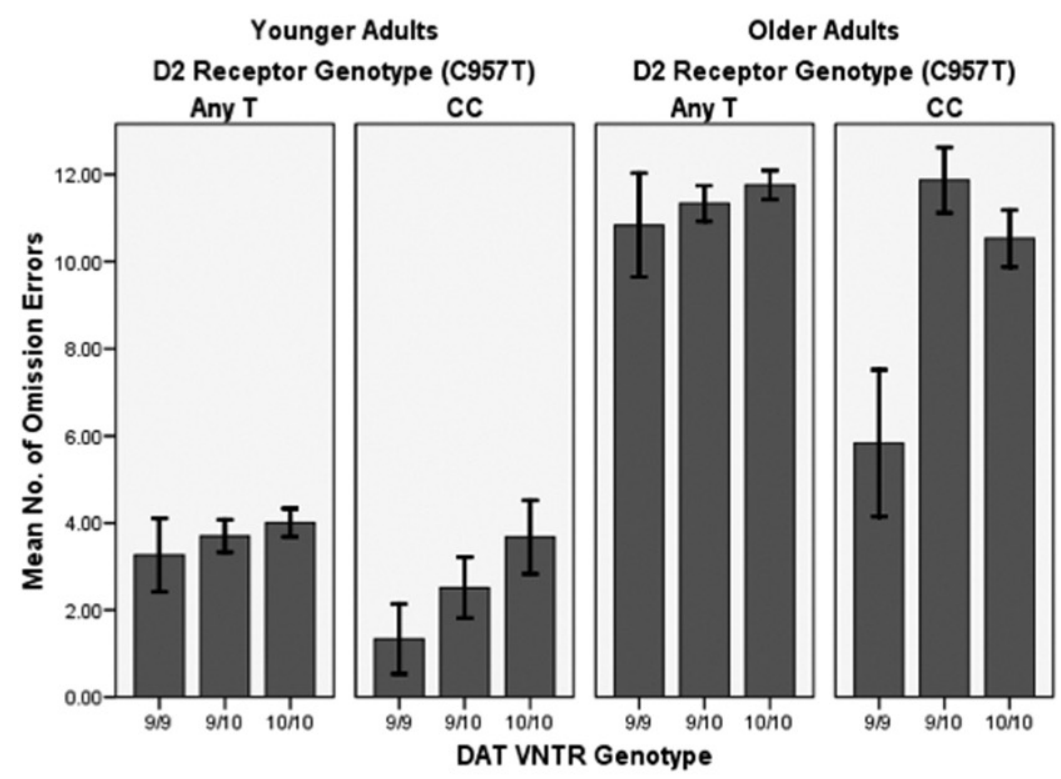

(B)

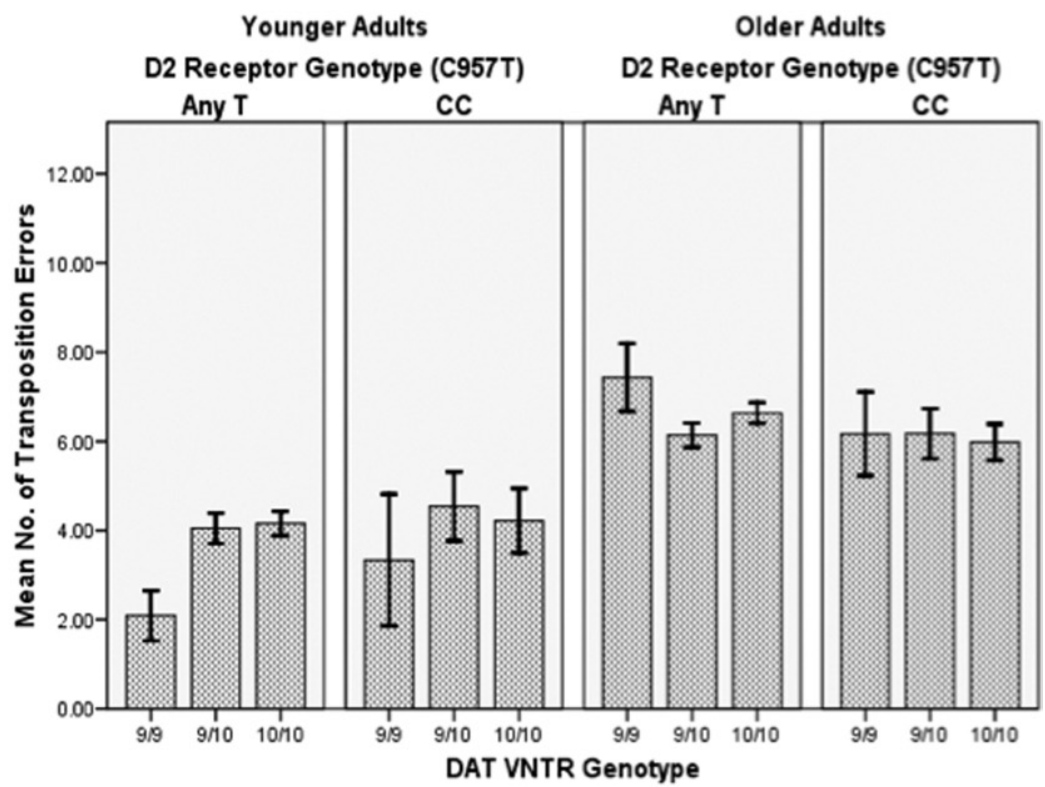

Fig. 2. Omission (A) and transposition (B) errors across age and genotype groups (error bars are standard errors around the means).

sistencies may also instantiate the inverse U-shaped function that relates dopamine signaling to performance (Cools and D'Esposito, 2011; Li and Sikström, 2002; Mattay et al., 2003; Vijayraghavan et al., 2007), with both deficient or excessive modulation being suboptimal for cognitive functions.

In conclusion, individual differences in genes that regulate synaptic DA levels (the DAT gene, SLC6A3) and the availability of $\mathrm{D} 2$ receptors (the $D R D 2$ gene) contribute to phenotype variations in backward serial recall, an episodic memory task with high encoding and retrieval demands. The genetic effect of higher synaptic DA levels was observed particularly in individuals who also carried the genotype associated with greater D2 receptor availability. Consistent with the resource-modulation hypothesis (Lindenberger et al., 2008) and the inverted-U function relating DA signaling and performance (Cools \& D'Esposito, 2011; Li \& Siktröm, 2002; Vijayraghavan et al., 2007), the interactive effect between the two genes on episodic memory was magnified in older adults whose pre- and postsynaptic DA functions in the frontostriatal circuitry are compromised. 


\section{Disclosure statement}

The authors disclose no conflicts of interest.

Participants gave informed consent and were paid €7 per hour for their participation. The ethics committee of the Charité Universitätsmedizin Berlin approved the study.

\section{Acknowledgements}

The authors thank Kirsten Becker, Ute Martin, Ludmila Müller, Caroline Stockmeyer and all other research assistants for their valuable help with the data collection.

This research was supported by the Max Planck Society, including a grant from the innovation fund (M.FE.ABild0006). It was also supported by a grant from the German Federal Ministry for Education and Research to the Berlin Imaging Center. Lars Bäckman was supported by grants from the Swedish Research Council, Swedish Brain Power, an Alexander von Humboldt Research Award, and a donation from the af Jochnick Foundation. Shu-Chen Li was also supported by grants from the German Science Foundation (DFG FOR 778) and the German Federal Ministry for Education and Research (BMBF Bernstein Fokus Neuronale Grundlagen des Lernes 01GQ0913). Goran Papenberg is a fellow of the International Max Planck Research School on the Life Course (LIFE).

\section{References}

Bäckman, L., Ginovart, N., Dixon, R.A., Wahlin, T.B., Wahlin, A., Halldin, C., Farde, L., 2000. Age-related cognitive deficits mediated by changes in the striatal dopamine system. Am. J. Psychiatry 157, 635637.

Bäckman, L., Lindenberger, U., Li, S.C., Nyberg, L., 2010. Linking cognitive aging to alterations in dopamine neurotransmitter functioning: recent data and future avenues. Neurosci. Biobehav. Rev. 34, 670-677.

Bäckman, L., Nyberg, L., Lindenberger, U., Li, S.C., Farde, L., 2006. The correlative triad among aging, dopamine, and cognition: current status and future prospects. Neurosci. Biobehav. Rev. 30, 791-807.

Bertolino, A., Blasi, G., Latorre, V., Rubino, V., Rampino, A., Sinibaldi, L., Caforio, G., Petruzzella, V., Pizzuti, A., Scarabino, T., Nardini, M., Weinberger, D.R., Dallapiccola, B., 2006. Additive effects of genetic variation in dopamine regulating genes on working memory cortical activity in human brain. J. Neurosci. 26, 3918-3922.

Bertolino, A., Fazio, L., Di Giorgio, A., Blasi, G., Romano, R., Taurisano, P., Caforio, G., Sinibaldi, L., Ursini, G., Popolizio, T., Tirotta, E., Papp, A., Dallapiccola, B., Borrelli, E., Sadee, W., 2009. Genetically determined interaction between dopamine transporter and the D2 receptor on prefronto-striatal activity and volume in humans. J. Neurosci. 28 , $1224-1234$.

Boonstra, A.M., Kooij, J.J., Buitelaar, J.K., Oosterlaan, J., Sergeant, J.A., Heister, J.G., Franke, B., 2008. An exploratory study of the relationship between four candidate genes and neurocognitive performance in adult ADHD. Am. J. Med. Genet. B Neuropsychiatr. Genet. 147, 397-402.

Botvinick, M., Watanabe, T., 2007. From numerosity to ordinal rank: a gain-field model of serial order representation in cortical working memory. J. Neurosci. 27, 8636-8642.

Brehmer, Y., Westerberg, H., Bellander, M., Fürth, D., Karlsson, S., Bäckman, L., 2009. Working memory plasticity modulated by dopamine transporter genotype. Neurosci. Lett. 467, 117-120.
Cervenka, S., Bäckman, L., Cselényi, Z., Halldin, C., Farde, L., 2008. Associations between dopamine D2-receptor binding and cognitive performance indicate functional compartmentalization of the human striatum. NeuroImage 40, 1287-1295.

Cheon, K.A., Ryu, Y.H., Kim, J.W., Cho, D.Y., 2005. The homozygosity for 10-repeat allele at dopamine transporter gene and dopamine transporter density in Korean children with attention deficit hyperactivity disorder: relating to treatment response to methylphenidate. Eur. Neuropsychopharmacol. 15, 95-101.

Cools, R., D'Esposito, M., 2011. Inverted-U-shaped dopamine actions on human working memory and cognitive control. Biol. Psychiatry 69, e113-e125.

Duan, J., Wainwright, M.S., Comeron, J.M., Saitou, N., Sanders, A.R., Gelernter, J., Gejman, P.V., 2003. Synonymous mutations in the human dopamine receptor D2 (DRD2) affect mRNA stability and synthesis of the receptor. Hum. Mol. Genet. 12, 205-216.

Ebbinghaus, H., 1885. Über das Gedächtnis. Untersuchungen zur experimentellen Psychologie. Duncker \& Humblot, Leipzig.

Egan, M.F., Kojima, M., Callicott, J.H., Goldberg, T.E., Kolachana, B.S., Bertolino, A., Zaitsev, E., Gold, B., Goldman, D., Dean, M., Lu, B., Weinberger, D.R., 2003. The BDNF val66met polymorphism affects activity-dependent secretion of BDNF and human memory and hippocampal function. Cell 112, 257-269.

Erixon-Lindroth, N., Farde, L., Wahlin, T.B., Sovago, J., Halldin, C., Bäckman, L., 2005. The role of the striatal dopamine transporter in cognitive aging. Psychiatry Res. 138, 1-12.

Farrell, S., Lewandowsky, S., 2002. An endogenous distributed model of ordering in serial recall. Psychon. Bull. Rev. 9, 59-79.

Fern, E.F., Monroe, K.B., 1996. Effect-size estimates: issues and problems in interpretation. J. Consum. Res. 23, 89-105.

Fortin, N.J., Agster, K.L., Eichenbaum, H.B., 2002. Critical role of the hippocampus in memory for sequences of events. Nat. Neurosci. 5, $458-462$.

Green, A.E., Munafò, M.R., DeYoung, C.G., Fossella, J.A., Fan, J., Gray, J.R., 2008. Using genetic data in cognitive neuroscience: from growing pains to genuine insights. Nat. Rev. Neurosci. 9, 710-720.

Hariri, A.R., Goldberg, T.E., Mattay, V.S., Kolachana, B.S., Callicott, J.H., Egan, M.F., Weinberger, D.R., 2003. Brain-derived neurotrophic factor val66met polymorphism affects human memory-related hippocampal activity and predicts memory performance. J. Neurosci. 23, 66906694.

Heinz, A., Goldman, D., Jones, D.W., Palmour, R., Hommer, D., Gorey, J.G., Lee, K.S., Linnoila, M., Weinberger, D.R., 2000. Genotype influences in vivo dopamine transporter availability in human striatum. Neuropsychopharmacology 22, 133-139.

Herlitz, A., Rehnman, J., 2008. Sex differences in episodic memory. Current Dir. Psychol. Sci. 17, 52-56.

Hirvonen, M.M., Laakso, A., Någren, K., Rinne, J.O., Pohjalainen, T., Hietala, J., 2009b. C957T polymorphism of dopamine D2 receptor gene affects striatal DRD2 in vivo availability by changing the receptor affinity. Synapse 63, 907-912.

Hirvonen, M.M., Lumme, V., Hirvonen, J., Pesonen, U., Någren, K., Vahlberg, T., Scheinin, H., Hietala, J., 2009a. C957T polymorphism of the human dopamine D2 receptor gene predicts extrastriatal dopamine receptor availability. Prog. Neuropsychopharmacol. Biol. Psychiatry $33,630-636$.

Hulme, C., Roodenrys, S., Schweickert, R., Brown, G.D., Martin, M., Stuart, G., 1997. Word-frequency effects on short-term memory tasks: evidence for a redintegration process in immediate serial recall. J. Exp. Psychol. Learn. Mem. Cogn. 23, 1217-1232.

Jacobsen, L.K., Pugh, K.R., Mencl, W.E., Gelernter, J., 2006. C957T polymorphism of the dopamine D2 receptor gene modulates the effect of nicotine on working memory performance and cortical processing efficiency. Psychopharmacology (Berl.) 188, 530-540.

Jacobsen, L.K., Staley, J.K., Zoghbi, S.S., Seibyl, J.P., Kosten, T.R., Innis, R.B., Gelernter, J., 2000. Prediction of dopamine transporter binding 
availability by genotype: a preliminary report. Am. J. Psychiatry 157 , $1700-1703$.

Kaasinen, V., Vilkman, H., Hietala, J., Någren, K., Helenius, H., Olsson, H., Farde, L., Rinne, J., 2000. Age-related dopamine D2/D3 receptor loss in extrastriatal regions of the human brain. Neurobiol. Aging 21, 683-688.

Kellendonk, C., Simpson, E.H., Polan, H.J., Malleret, G., Vronskaya, S., Winiger, V., Moore, H., Kandel, E.R., 2006. Transient and selective overexpression of dopamine D2 receptors in the striatum causes persistent abnormalities in prefrontal cortex functioning. Neuron 49, 603 615.

Kimberg, D.Y., Aguirre, G.K., Lease, J., D’Esposito, M., 2001. Cortical effects of bromocriptine, a D-2 dopamine receptor agonist, in human subjects, revealed by fMRI. Hum. Brain Mapp. 12, 246-257.

Kimmel, H.L., Joyce, A.R., Carroll, F.I., Kuhar, M.J., 2001. Dopamine D1 and D2 receptors influence dopamine transporter synthesis and degradation in the rat. J. Pharmacol. Exp. Ther. 298, 129-140.

Landau, S.M., Lal, R., O’Neil, J.P., Baker, S., Jagust, W.J., 2009. Striatal dopamine and working memory. Cereb. Cortex 19, 445-454.

Lee, F.J., Pei, L., Moszczynska, A., Vukusic, B., Fletcher, P.J., Liu, F., 2007. Dopamine transporter cell surface localization facilitated by a direct interaction with the dopamine D2 receptor. EMBO J. 26, $2127-$ 2136.

Lewandowsky, S., Murdock, B.B., Jr, 1989. Memory for serial order. Psychol. Rev. 96, 25-57.

Li, S.C., Lindenberger, U., Sikström, S., 2001. Aging cognition: from neuromodulation to representation. Trends Cogn. Sci. 5, 479-486.

Li, S.C., Sikström, S., 2002. Integrative neurocomputational perspectives on cognitive aging, neuromodulation, and representation. Neurosci. Biobehav. Rev. 26, 795-808.

Li, S.C., Chicherio, C., Nyberg, L., von Oertzen, T., Nagel, I.E., Papenberg, G., Sander, T., Heekeren, H.R., Lindenberger, U., Bäckman, L., 2010. Ebbinghaus revisited: influences of the BDNF Val66Met polymorphism on backward serial recall are modulated by human aging. J. Cogn. Neurosci. 22, 2164-2173.

Li, S.-C., Lewandowsky, S., 1993. Intralist distractors and recall direction: constraints on models of memory for serial order. J. Exp. Psychol. Learn. Mem. Cogn. 19, 895-918.

Li, S.-C., Lewandowsky, S., 1995. Forward and backward recall: different retrieval processes. J. Exp. Psychol. Learn. Mem. Cogn. 21, 837-847.

Lindenberger, U., Nagel, I.E., Chicherio, C., Li, S.C., Heekeren, H.R., Bäckman, L., 2008. Age-related decline in brain resources modulates genetic effects on cognitive functioning. Front. Neurosci. 2, 234-244.

Lisman, J.E., Grace, A.A., 2005. The hippocampal-VTA loop: Controlling the entry of information into long-term memory. Neuron 46, 703-713.

Loo, S.K., Specter, E., Smolen, A., Hopfer, C., Teale, P.D., Reite, M.L., 2003. Functional effects of the DAT1 polymorphism on EEG measures in ADHD. J. Am. Acad. Child Adolesc. Psychiatry 42, 986-993.

Markett, S., Montag, C., Walter, N. T., Reuter, M., 2011. Evidence for the modality independence of the genetic epistasis between the dopaminergic and cholinergic system on working memory capacity. Eur. Neuropsychopharma. 21, 216-220.

Marshuetz, C., Smith, E.E., 2006. Working memory for order information: multiple cognitive and neural mechanisms. Neuroscience 139, 195200.

Mattay, V.S., Goldberg, T.E., Fera, F., Hariri, A.R., Tessitore, A., Egan, M.F., Kolachana, B., Callicott, J.H., Weinberger, D.R., 2003. Catechol O-methyltransferase val158-met genotype and individual variation in the brain response to amphetamine. Proc. Natl. Acad. Sci. U. S. A. 100, 6186-6191.

Maxwell, S.E., Camp, C.J., Arvey, R.D., 1981. Measures of strength of association: a comparative examination. J. Appl. Psychol. 66, 525-534.

Maylor, E.A., Vousden, J.I., Brown, G.D., 1999. Adult age differences in short-term memory for serial order: data and a model. Psychol. Aging $14,572-594$
Meyer-Lindenberg, A., Weinberger, D.R., 2006. Intermediate phenotypes and genetic mechanisms of psychiatric disorders. Nat. Rev. Neurosci. 7, 818-827.

Miller, G.M., Madras, B.K., 2002. Polymorphisms in the 3'-untranslated region of human and monkey dopamine transporter genes affect reporter gene expression. Mol. Psychiatry 7, 44-55.

Mitchell, R.J., Howlett, S., Earl, L., White, N.G., McComb, J., Schanfield, M.S., Briceno, I., Papiha, S.S., Osipova, L., Livshits, G., Leonard, W.R., Crawford, M.H., 2000. Distribution of the 3' VNTR polymorphism in the human dopamine transporter gene in world populations. Hum. Biol. 72, 295-304.

Morcom, A.M., Bullmore, E.T., Huppert, F.A., Lennox, B., Praseedom, A., Linnington, H., Fletcher, P.C., 2010. Memory encoding and dopamine in the aging brain: A psychopharmacological neuroimaging study. Cereb. Cortex 20, 743-757.

Mozley, L.H., Gur, R.C., Mozley, P.D., Gur, R.E., 2001. Striatal dopamine transporters and cognitive functioning in healthy men and women. Am. J. Psychiatry 158, 1492-1499.

Nagel, I.E., Chicherio, C., Li, S.C., von Oertzen, T., Sander, T., Villringer, A., Heekeren, H.R., Bäckman, L., Lindenberger, U., 2008. Human aging magnifies genetic effects on executive functioning and working memory. Front. Hum. Neurosci. 2, 1-8.

Pezawas, L., Verchinski, B.A., Mattay, V.S., Callicott, J.H., Kolachana, B.S., Straub, R. E., Egan, M. F., Meyer-Lindenberg, A., Weinberger, D. R., 2004. The brain-derived neurotrophic factor val66met polymorphism and variation in human cortical morphology. J Neurosci. 10, 10099-100102.

Posner, M.I., Rothbart, M.K., Sheese, B.E., 2006. Attention genes. Dev. Sci. 10, 24-29.

Preuschhof, C., Heekeren, H. R., Li, S.-C., Sander, T., Lindenberger, U., Bäckman, L., 2010. KIBRA and CLSTN2 polymorphisms exert interactive effects on human episodic memory. Neuropsychologia 48, 402208.

Raz, N., Rodrigue, K.M., Kennedy, K.M., Land, S., 2009. Genetic and vascular modifiers of age-sensitive cognitive skills: effects of COMT, BDNF, ApoE, and Hypertension. Neuropsychology 23, 105-116.

Rinne, J. O., Sahlberg, N., Ruottinen, H., Nurmi, E., Bergman, J., Haaparanta M., Solin, O., 1998. Striatal uptake of the dopamine reuptake ligrand [11C]beta-CFT is reduced in Alzheimer's disease assessed by positron emission tomography. Neurology 50, 152-156.

Rommelse, N.N., Altink, M.E., Arias-Vásquez, A., Buschgens, C.J., Fliers, E., Faraone, S.V., Buitelaar, J.K., Sergeant, J.A., Franke, B., Oosterlaan, J., 2008. A review and analysis of the relationship between neuropsychological measures and DAT1 in ADHD. Am. J. Med. Genet. B Neuropsychiatr. Genet. 147B, 1536-1546.

Schott, B.H., Seidenbecher, C.I., Fenker, D.B., Lauer, C.J., Bunzeck, N., Bernstein, H.G., Tischmeyer, W., Gundelfinger, E.D., Heinze, H.J., Düzel, E., 2006. The dopaminergic midbrain participates in human episodic memory formation: Evidence from genetic imaging. J. Neurosci. 26, 1407-1417.

Seamans, J.K., Yang, C.R., 2004. The principal features and mechanisms of dopamine modulation in the prefrontal cortex. Prog. Neurobiol. 74, $1-57$.

Shohamy, D., Adcock, R.A., 2010. Dopamine and adaptive memory. Trends Cogn. Sci. 14, 464-472.

Simon, J.R., Stollstorff, M., Westbay, L.C., Vaidya, C.J., Howard, J.H., Howard, D.V., 2011. Dopamine transporter genotype predicts implicit sequence learning. Behav. Brain Res. 216, 452-457.

Störmer, V.S., Passow, S., Biesenack, J., Li, S.C., 2011. Dopaminergic and cholinergic modulations of visual-spatial attention and working memory: insights from molecular genetic research and implications for adult cognitive development. Dev. Psychol. 48, 875-889.

Takahashi, H., Kato, M., Hayashi, M., Okubo, Y., Takano, A., Ito, H., Suhara, T., 2007. Memory and frontal lobe functions; possible relations with dopamine D2 receptors in the hippocampus. NeuroImage 34, 1643-1649. 
Talmi, D., Grady, C.L., Goshen-Gottstein, Y., Moscovitch, M., 2005. Neuroimaging the serial position curve. A test of single-store versus dual-store models. Psychol. Sci. 16, 716-723.

Thomas, J.G., Milner, H.R., Haberlandt, K.F., 2003. Forward and backward recall: different response time patterns, same retrieval order. Psychol. Sci. 14, 169-174.

Troiano, A.R., Schulzer, M., de la Fuente-Fernandez, R., Mak, E., Mckenzie, J., Sossi, V., McCormick, S., Ruth, T.J., Stoessl, A.J., 2010. Dopamine transporter PET in normal aging: dopamine transporter decline and its possible role in preservation of motor function. Synapse 64, 146-151.

Unsworth, N., Engle, R.W., 2006. A temporal-retrieval account of complex span: an analysis of errors. J. Mem. Lang. 54, 346-362.

van de Giessen, E., de Win, M.M., Tanck, M.W., van den Brink, W., Baas, F., Booij, J., 2009. Striatal dopamine transporter availability associated with polymorphisms in the dopamine transporter gene SLC6A3. J. Nucl. Med. 50, 45-52.

Vandenbergh, D.J., Persico, A.M., Hawkins, A.L., Griffin, C.A., Li, X., Jabs, E.W., Uhl, G.R., 1992. Human dopamine transporter gene
(DAT1) maps to chromosome 5p15.3 and displays a VNTR. Genomics 14, 1104-1106.

VanNess, S.H., Owens, M.J., Kiltes, C.D., 2005. The variable number of tandem repeats element in DAT1 regulates in vitro dopamine transporter density. BMC Genet. 6, 55 .

Vijayraghavan, S., Wang, M., Birnbaum, S.G., Williams, G.V., Arnsten, A.F., 2007. Inverted-U dopamine D1 receptor actions on prefrontal neurons engaged in working memory. Nat. Neurosci. 10, 376-384.

Wahlstrom, D., White, T., Luciana, M., 2010. Neurobehavioral evidence for changes in dopamine system activity during adolescence. Neurosci. Biobehav. Rev. 34, 631-648.

Weinberger, D.R., Egan, M.F., Bertolino, A., Callicott, J.H., Mattay, V.S., Lipska, B.K., Berman, K.F., Goldberg, T.E., 2001. Prefrontal neurons and the genetics of schizophrenia. Biol. Psychiatry 50, $825-844$.

World Health Organization, International Society of Hypertension Writing Group. 2003. Statement on management of hypertension. J. Hypertension 21, 1981-1991. 